\title{
THE FREEZING POINT OF IRIDIUM
}

\author{
By F. Henning ${ }^{1}$ and H. T. Wensel ${ }^{2}$
}

ABSTRACT

The ratio of brightness for red light of a black body immersed in freczing iridium to that of a similar black body immersed in freezing gold was measurer both directly and indirectly. The indirect method consisted in determining the ratio of brightness at the iridium and platinum freezing points and calculating the result from the previously determined platinum to gold ratio. The two methods, agreeing with each other within experimental errors, yiclded a value for the iridium to gold ratio of 4,380 at wave length $0.652 \mu$. This fixes the freezing point of iridium on the International Temperature Scale as $2,454^{\circ} \mathrm{C}$.

\section{CONTENTS}

I. Introduction

II. Previous work

III. Present work

1. The iridinin

2. The furnace and

3. Method of observation $\quad$ S14

4. Determination of effective wave length $\ldots \ldots 14$

IV. Results

VI. Summary Acknowledgments

VII. Appendix. Preparation and purity of iridium 819

\section{INTRODUCTION}

In making an accurate determination of the freezing or melting temperature of a pure metal, one of the objects is usually a more accurate establishment of the temperature scale in practical use by providing an additional known fixed point at which temperature measuring equipment may be checked. In the present work, however, this item was of comparatively small importance. The extremely high cost of the metal, the difficulty of purifying it to the required degree, and the difficulties encountered in melting the metal under suitable conditions prohibit its use as a secondary thermometric fixed point except in very unusual cases. Indeed these factors would have rendered the result obtained in the present work scarcely worth the effort put forth were it not for the fact that data were obtained which are greatly needed in connection with standards in other fields.

The color temperature scales used by various laboratories are not on a very satisfactory basis. Not much is linown concerning the agreement of these scales and in some cases even the basis for the

1 Chief of the Division of Heat and Pressure, Physikalisch-Technische Reichsanstalt. This investign1 Chief of the Division of Heat and Pressure, Physikalisch-Technische Reichsanstal fiersonnel between
tion was carried out at the Bureau of Standards under an arrangement for an exchange of fer these institutions.

${ }^{2}$ Chief of the Pyrometry Section, Bureau of Standards. 
scale is not definitely set forth. A project is under way at the Bureau of Standards to establish a color temperature scale based on the colors of black bodies maintained at the freezing points of platinum, rhodium, and iridium. For this, accurate values for the temperatures of these fixed points are essential.

The primary purpose, however, for which this work was undertaken was to secure data bearing upon the basic standards in the field of photometry. If a carbon filament electric lamp operating at the color temperature of the platinum point be photometered against a black body immersed in freezing platinum ${ }^{3}$ and a tungsten electric lamp operating at the color temperature of the iridium point be photometered against a black body immersed in freezing iridium, then the relative candlepowers of these two lamps can be calculated from the temperatures of the two black bodies employed. This provides a method for comparing two photometric standard lamps differing widely in color which avoids the difficulties met with in heterochromatic photometry.

These two applications of the black body immersed in freezing iridium will be reported in subsequent papers and have been mentioned here merely to explain why extreme accuracy was sought in this determination of the freezing temperature.

\section{PREVIOUS WORK}

For the past 25 years the value $2,350^{\circ} \mathrm{C}$. has been almost universally accepted as the melting point of iridium. It appears in practically all the tables of melting points, such as those of Landolt and Börnstein, and is listed in the International Critical Tables as $23_{50}$, indicating that this value is uncertain by at least $100^{\circ}$. After the present work had yielded a value some $100^{\circ} \mathrm{C}$. higher than this, a critical analysis of the literature led to the conclusion that previous work alone indicated the freezing point of iridium to be $2,435^{\circ} \mathrm{C}$. with an uncertainty of perhaps $25^{\circ}$ or $30^{\circ} \mathrm{C}$. In view of this condition it was thought advisable to discuss the published work in greater detail than would otherwise seem warranted.

The high temperature scale is defined by the equation

$$
\frac{1}{t+273}=\frac{1}{t_{A u}+273}-\frac{\lambda \log _{e} \frac{J}{J_{A u}}}{C_{2}}
$$

in which $t$ is the temperature in degrees centigrade, $t_{A u}$ is the temperature of freezing or melting gold, $\frac{J}{J_{A u}}$ is the ratio of the intensities of the radiation at wave length $\lambda$ emitted by black bodies at the above two temperatures, and $C_{2}$ is a constant. A measurement of $\frac{J}{J_{A u}}$, together with a determination of the corresponding $\lambda$, obviously determines $t$, once $t_{A u}$ and $C_{2}$ are fixed. It is equally obvious that a change in the value assigned to either $\dot{C}_{2}$ or the gold point will produce a change in the numerical value of $t$. During the past 30 years some 10 or 12 different values have at some time or other been assigned

\footnotetext{
The Waidner-Burgess Standard of Light, B.S.Jour. Research, vol. 6, p. 1103, 1931.
} 
to $C_{2}$, the value on the present International Temperature Scale ${ }^{4}$ being $1.432 \mathrm{~cm}$ degrees. The gold point on this scale is defined as $1,063^{\circ} \mathrm{C}$. The utility of a temperature determination which has been made by measuring $\lambda$ and the ratio of brightness is not aflected when a new scale is adopted, since the numerical value of the temperature may be equally well calculated on the new scale. It is essential, however, to reduce such values to a common scale for purposes of comparison.

The earliest experiments of any consequence on the temperature of the iridium point are those of Nernst, ${ }^{5}$ who measured the brightness of black bodies at the platinum and iridium points in terms of the Hefner Kerze. The values first reported were, respectively, 91 and 1,210 H.K. per $\mathrm{cm}^{2}$. Light of the whole spectrum was used instead of monochromatic light, so that equation (1) cannot be applied. Nernst calculated the temperature of the iridium point as $2,203^{\circ} \mathrm{C}$. on the assumption that the brightness of a black body is 47 H.K. per $\mathrm{cm}^{2}$ at $1,690^{\circ} \mathrm{C}$. and varies as the fourteenth power of the absolute temperature. On the basis of our present knowledge of the relation between the photometric brightness and temperature it is possible to calculate the iridium point from the ratio 1,210 to 91 obtained by Nernst at the iridium and platinum points. Nernst ${ }^{6}$ himself, however, showed later that due to contamination of his platinum specimens with iridium, the temperature of the furnace in his first work had been about $50^{\circ} \mathrm{C}$. above the platinum point when the brightness was measured as $91 \mathrm{H} . \mathrm{K}$. per $\mathrm{cm}^{2}$. Taking precautions to avoid this contamination in his later work, he obtained a value of $63.4 \mathrm{H}$.K. per $\mathrm{cm}^{2}$.

Nernst made an attempt to express his 1906 results in terms of the Reichsanstalt scale and obtained the value $2,348^{\circ}$, which is equivalent to $2,394^{\circ} \mathrm{C}$. on the present scale. However, this value is dependent on the degree of success which Nernst met with in making the transfer, and a more reliable value can be deduced directly from the measured ratio of brightness $1,210 / 63.4$.

Calculation based on the I.C.I. ${ }^{7}$ visibility factors shows that two black bodies, one at $2,428^{\circ} \mathrm{C}$. and the other at the platinum point, taken as $1,773.5^{\circ} \mathrm{C} .^{8}$ will have a ratio of brightness $1,210 / 63.4$ for a normal observer. The ratio measured by Nernst, therefore, leads directly to a value of $2,428^{\circ} \mathrm{C}$. (Int.) for the iridium point, which is probably the best one to be found in the literature, since it is independent of the photometric unit used and depends only on the purity of the metals and the accuracy with which the ratio determined corresponds to that for a normal observer.

Mendenhall and Ingersoll ${ }^{9}$ determined the melting point of minute bits of iridium placed on top of a Nernst glower. The temperature

\footnotetext{
- Proc. Seventh Gen. Conf. of Weights and Measures, p. 56, 1927; Text in annex 4, p. 94; B.S.Jour

Research, vol. 1, p. 635, 1928; Zs. f. Phys., vol. 49, p. 742, 1928.

Phys. Zeits., vol. 4, p. 733, 1903.

7 Recueil des Travaux, I.C.I., 16th session (Ceneva), p. 67, 1924. See also R.S.Sci. Papers, rol. 16, p. 131. $1923-24$.

8 B.S.Jour. Research, ro!. 6, p. 1119, 193 !.

- Phys. Rev., voi. 25, p. 1, 1907.
} 
of the glower was obtained by extrapolation of the empirical isochromatic radiation formula

$$
\log E=K_{1}+\frac{K_{2}}{t+273}
$$

The gold point, taken as $1,065^{\circ} \mathrm{C}$. and the platinum point, taken as $1,745^{\circ}$ or $1,789^{\circ} \mathrm{C}$., were used to determine the necessary constants. The iridium point was reported as $2,292^{\circ}$ or $2,388^{\circ}$ C., according to the value accepted for the platinum point.

The paper does not mention the values obtained for either the $E$ 's or the $K^{\prime}$ 's in equation (2). From the two values of the iridium point calculated from the two corresponding platinum points, however, it is possible to solve for the $K^{\prime}$ 's in equation (2) and deduce a value of $2,360^{\circ} \mathrm{C}$. on the basis of the gold point being $1,063^{\circ}$ and the platinum point $1,773.5^{\circ} \mathrm{C}$. However, the results are stated to be consistent with a value of $C_{2}=1.65 \mathrm{~cm}$ degrees. If their mean values for platinum, iridium, and $C_{2}$ are used, a recalculation on the basis of present data $\left(C_{2}=1.432\right.$ and $P t=1,773.5^{\circ}$ C. $)$ yields the value $2,468^{\circ}$ C. for the iridium point. Neither of these methods of calculation is free from objection and we can only conclude that the result corresponds to a value between $2,360^{\circ}$ and $2,468^{\circ}$ C., the mean of which is $2,414^{\circ} \mathrm{C}$.

In 1905 Holborn and Henning ${ }^{10}$ reported a value of $2,000^{\circ} \mathrm{C}$. for the apparent temperature of melting iridium measured at wave length $0.643 \mu$ and using $1.45 \mathrm{~cm}$ degrees for $C_{2}$. No attempt was made to convert the value obtained to true temperature while the fact that the reported value was rounded to the nearest $100^{\circ}$ indicates its approximate nature. However, five years later H. von Wartenberg ${ }^{11}$ determined the reflection factors for a number of metals and used the value 0.752 (emissivity 0.248 ) obtained for iridium to convert the value of Holborn and Henning to true temperature. The value there calculated reduces to $2,407^{\circ} \mathrm{C}$. (Int.).

Von Wartenberg ${ }^{11}$ also reported a value of $2,360^{\circ} \mathrm{C}$. measured by himself on the basis of $1,745^{\circ} \mathrm{C}$. for the platinum point and $1.46 \mathrm{~cm}$ degrees for $C_{2}$. This value becomes $2,425^{\circ} \mathrm{C}$. on the present scale $\left(C_{2}=1.432 \mathrm{~cm}\right.$ degrees $)$ if the platinum point be taken as 1,773.5.

In 1916, Burgess ${ }^{12}$ reported a value of $2,400^{\circ} \mathrm{C}$. which reduces to $2,418^{\circ}$ C. (Int.), but the value was reported as doubtful.

An accurate value for the apparent temperature of the iridium point was obtained by Henning and Heuse ${ }^{13}$ in 1924. The value, $2,068^{\circ} \mathrm{C}$. was found for wave length $0.622 \mu$. Using $\mathrm{v}$. Wartenberg's value of 0.248 for the emissivity, this reduces to $2,458^{\circ} \mathrm{C}$. (Int.).

A change of 10 percent in the value of the emissivity used, however, will result in a change of about $30^{\circ}$ in the result. If, therefore, the temperature be calculated on the basis of an emissivity of 0.3 as found by Burgess and Waltenberg ${ }^{14}$ the value, $2,395^{\circ} \mathrm{C}$. is obtained for the melting point.

Since the presentation of the present work ${ }^{15}$ before the Optical Socicty of America, October 22, 1931, von Wartenberg, Werth, and

10 Berl. Ber., p. 317, 1905.

II Verh. Jeut. Phys. Gesell., vol. 12, p. 105, 1910; and vol. 12, p. 121, 1910.

12 J. Frank. Inst., vol. 182 p. 19, 1916.

13 Zeits. \&. Physik., vol. 29, p. 157, 1924.

14 B.S. Bull., vol. 11, p. 591, 1915.

15 J. Opt. Soc. Am., vol. 22, 1, p. 7, January 1932. 
Reusch ${ }^{16}$ have reported a value of $2,440^{\circ} \pm 25^{\circ}$ C. The ralues obtained, however, ranged from $2,390^{\circ}$ to $2,470^{\circ} \mathrm{C}$.

The mean of the seven determinations listed in table 1 is $2,424^{\circ} \mathrm{C}$ with an uncertainty of perhaps $40^{\circ}$. A weighted mean of the abovo values would undoubtedly be subject to a lesser uncertainty, but, instead of assigning weights, three values obtained by three different methods have been starred in table 1. Each of these strired values is, in our opinion, the best one for a particular method. The averucre of these three values is $2,442^{\circ} \mathrm{C}$. with an uncertainty of perhaps $25^{\circ} \mathrm{C}$.

TABLE 1.-Summary of values previously reported for the melting poinl of iridium

\begin{tabular}{|c|c|c|c|c|c|c|}
\hline \multirow{3}{*}{ Observers } & \multirow{3}{*}{ Year } & \multirow{3}{*}{ Scale used } & \multicolumn{3}{|c|}{ Temperature } & \multirow{3}{*}{ Remarks } \\
\hline & & & \multicolumn{2}{|c|}{ Reported } & \multirow{2}{*}{$\begin{array}{c}\text { Inter- } \\
\text { national } \\
\text { scale }\end{array}$} & \\
\hline & & & $\begin{array}{l}\text { Appar- } \\
\text { ent }\end{array}$ & True & & \\
\hline Nernst.- & 1903 & $B=63.4\left(\frac{t+273}{1,690}\right)^{14}$ & ${ }^{\circ} C$. & $\begin{array}{l}\circ C . \\
2,203\end{array}$ & ${ }^{\circ} C$. & Scale indefinite. \\
\hline Do_- & 1906 & $\begin{array}{l}\text { Gold point, } 1,064 ; C_{2}=1.46 \\
\mathrm{~cm} \text { degrees. }\end{array}$ & & 2,348 & $2,42 S^{*}$ & $\begin{array}{l}\text { Calculated directly from } \\
\text { Nernst's measure- } \\
\text { ments. }\end{array}$ \\
\hline $\begin{array}{l}\text { Mendenhall and } \\
\text { Ingersoll. }\end{array}$ & 1907 & $\begin{array}{l}\text { Gold point, } 1,065 ; \text { plat- } \\
\text { inum point, } 1,789 ; C_{2}= \\
1.65 \mathrm{~cm} \text { degrees. }\end{array}$ & & 2,388 & $2,414 ?$ & $\begin{array}{l}\text { Conversion to Interna- } \\
\text { tional scale very uncer- } \\
\text { tain. }\end{array}$ \\
\hline $\begin{array}{l}\text { Holborn and Hen- } \\
\text { ning. }\end{array}$ & 1905 & $\begin{array}{l}\text { Gold point, } 1,064 ; C_{2}=1.46 \\
\mathrm{~cm} \text { degrees. }\end{array}$ & 2,000 & & & $\begin{array}{l}\text { True temperature cal- } \\
\text { culated by } \mathrm{v} \text {. Warten- }\end{array}$ \\
\hline v. Wartenberg...-- & 1910 & $\begin{array}{l}\text { Computed value from } \\
\text { work of Holborn and } \\
\text { Henning. }\end{array}$ & & 2,348 & 2,394 & $\begin{array}{l}\text { berg from work of } \\
\text { Holborn and Henning } \\
\text { taking emissivity as } \\
0.248 \text {. }\end{array}$ \\
\hline Do_............. & 1910 & $\begin{array}{l}\text { Platinum point, } 1,745 ; C_{2} \\
\quad=1.46 \mathrm{~cm} \text { degrees. }\end{array}$ & & 2,360 & 2,425 & $\begin{array}{l}\text { Emissirity taken as } \\
0.24 \mathrm{~S} \text {. }\end{array}$ \\
\hline Burgess ............. & 1916 & $\begin{array}{l}\text { Gold point, } 1,063 ; C_{2}= \\
1.445 \mathrm{~cm} \text { degrees. }\end{array}$ & & 2,400 & 2,418 & Value reported as doubt- \\
\hline $\begin{array}{l}\text { Henning and } \\
\text { Heuse. }\end{array}$ & 1924 & $\begin{array}{l}\text { Gold point, } 1,063 ; C_{2}=1.43 \\
\text { cm degrees. }\end{array}$ & 2,068 & & $2,458^{*}$ & $\begin{array}{l}\text { Emissivity taken as } \\
0.248 \text {. }\end{array}$ \\
\hline $\begin{array}{l}\text { Wartenberg, } \\
\text { W erth, and } \\
\text { Reusch. }\end{array}$ & 1932 & International . . & & 2,440 & $2,440^{*}$ & $\begin{array}{l}\text { Range of values } 2,390 \text { to } \\
2,470 \text {. }\end{array}$ \\
\hline
\end{tabular}

\section{PRESENT WORK}

\section{THE IRIDIUM}

The iridium used in this work is believed to have contained less than 0.01 percent of metallic impurities, undoubtedly the first iridium that has been prepared in a state of purity even approaching this. The production of iridium of this purity is considered to be of such significance that we have requested Dr. E. Wichers to describe, in the appendix, the special methods which were used in preparing the sponge.

The melting of the sponge and the preparation of an ingot which would fit into the crucible and into which a sight tube or black body could be inserted was not by any means a simple matter. Because of the high melting point, it was not considered advisable to attempt the casting of an ingot as can so easily be done with platinum.

${ }_{16}$ Zs. f. Elektrochem., vol. 38, p. 50, 1932. 
The sponge was compressed to a specific gravity of about 12 or 14 and several compressed pellets placed in a crucible of the kind used in the actual observations. The compressed sponge suffered considerable shrinkage in the melting and additional pellets were added after each melting until an ingot of approximately $200 \mathrm{~g}$ and specific gravity of 22.5 was obtained.

After the ingot was removed from the crucible it was found that distortion of the crucible caused sufficient change in the shape of the ingot to prevent its fitting a new crucible. The ingot was therefore hot swaged by hand until it fitted loosely into a new crucible.

Iridium of high purity is extremely difficult to drill. It was found that a hole $3.5 \mathrm{~mm}$ in diameter could be laboriously drilled along the axis with drills tipped with tungsten carbide.

After swaging and drilling, the ingot was immersed for about 30 minutes in molten potassium pyrosulphate to remove surface contamination.

\section{THE FURNACE AND CRUCIBLE}

The arrangement of crucible, immersed black body or sight tube, insulation, and metal was identical with that used in the work on the Waidner-Burgess Standard of Light ${ }^{17}$ and shown there in figures 1 and 2. The advantages to be gained from the use of the induction furnace are likewise described there.

The only difference between the work on platinum and iridium, aside from the metals used, lay in the fact that in the latter case the crucibles and sight tubes were fired to a temperature of about $2,500^{\circ} \mathrm{C}$. before use. This was done in the induction furnace by placing the crucibles inside a graphite cylinder with zirconium oxide packed between the crucible and the graphite cylinder. In firing the crucibles in this way a layer of the zirconium oxide packing next to the graphite was contaminated with carbon, but the crucibles were not affected.

\section{METHOD OF OBSERVATION}

The method of observation and the pyrometer used were the same as were used in determining the freezing point of platinum ${ }^{18}$ and the measurement of the ratio of brightness from gold to iridium was made in two steps as there described. The observations on the black body immersed in iridium were taken through a sector disk with an opening of $2^{\circ} 44^{\prime} 38^{\prime \prime}$ (transmission 0.7622 percent). The lamp was consequently operated at a temperature of about $1,425^{\circ} \mathrm{C}$. The exact value of this temperature was determined by means of a second sector with an opening of $9^{\circ} 27^{\prime} 16^{\prime \prime}$ (transmission 2.626 percent). The combination of the two sectors corresponded to the ratio of brightness from the iridium point to a temperature within about $10^{\circ}$ of the gold point. Four observers participated in determining the ratio of brightness at the iridium point to that at the gold point.

After making a series of nine freezes, the iridium was allowed to cool to room temperature. Upon melting the iridium again, it was found that the sight tube was broken and it was therefore necessary to again swage, drill, and treat with molten potassium pyrosulphate. We have found it necessary to mount the iridium ingot in a new crucible each time it has been cooled to room temperature after a series of observations. 
Additional data for calculating the iridium point in terms of the platinum point were obtained by measuring the ratio of brightnessiridium to platinum. This was done by operating the pyrometer lamp at the platinum point and making observations on the black body immersed in freezing platinum and, through a sector of 6.96 percent transmission, on the black body immersed in freezing iridium.

This operating temperature is above the range in which pyrometer lamps are customarily operated. By taking readings on platinum before and after the readings on iridium, however, the effect of any change in the lamp, if not too large, will be eliminated. As a matter of fact it was found that the total change in the lamp during this phase of the work corresponded to a difference of only $0.3^{\circ} \mathrm{C}$. in the value of the iridium point.

In this part of the work only three observers participated as the work could not be completed during the two months' exchange of personnel.

\section{DETERMINATION OF EFFECTIVE WAVE LENGTH}

Due to the large temperature step from the gold point to the iridium point the individual characteristics of the observers' cyes produce a noticeable effect. For this reason it was decided not to use the same effective wave length; that is, the average for all the observers, in calculating the results as was done in the determination of the platinum point. ${ }^{19}$ Moreover, it was necessary to know the effective wave length very accurately. For this reason the following investigation was carried out.

A reflecting test plate of milk glass smoked with magnesium oxide was illuminated by a tungsten lamp operating at a color temperature of approximately $2,600^{\circ} \mathrm{K}$. The distance between this lamp which will be called the source and the test plate was adjusted until the optical pyrometer indicated about $1,300^{\circ} \mathrm{K}$. when sighted upon this test plate with no absorption device interposed. The observer matched the brightness of the lamp filament, whose color temperature was near the gold point, with that of the test plate, whose color temperature was near the iridium point.

Eight men from other sections of the Bureau, whose visual characteristics had been determined by Gibson and Tyndall ${ }^{20}$ so that the effective wave length of the red screen used could be calculated for each of the eight, were compared with the men who made the observations on the freezing point of iridium. The method of making the comparisons was as follows: Four settings were made by observer $\Lambda$, then four by observer B, four more by observer A, four more by observer B, and finally four by observer A.

Let the effective wave length of the red screen for the temperature interval in question, calculated on the basis of A's visibility, be $\lambda_{A}$ and let that for observer $\mathrm{B}$, which is to be determined, be $\lambda_{B}$. Further let $\theta_{3}$ be the color temperature of the source, $\theta_{A}$ the apparent brightness temperature of the test plate determined from the pyrometer settings of $A$, and let $\theta_{A}+\Delta \theta_{A}$ be the corresponding value determined from the pyrometer settings of observer $B$.

10 See footnote 18 p. 814 .

20 B.S. Bull., vol. 19, p. 131, 1923. 
and

$$
\frac{1}{\theta_{s}}-\frac{1}{\theta_{A}}=\frac{\lambda_{A} \log _{e} R}{C_{2}}
$$

Hence

$$
\frac{1}{\theta_{s}}-\frac{1}{\theta_{A}+\Delta \theta_{A}}=\frac{\lambda_{B} \log _{e} R}{C_{2}}
$$

or

$$
\begin{gathered}
\frac{\frac{1}{\theta_{s}}-\frac{1}{\theta_{A}}}{\frac{1}{\theta_{s}}-\frac{1}{\theta_{A}+\Delta \theta_{A}}}=\frac{\lambda_{A}}{\lambda_{B}} \\
1+\frac{\theta_{s} \Delta \theta_{A}}{\theta_{s} \theta_{A}-\theta_{A}{ }^{2}-\theta_{A} \Delta \theta_{A}}=1-\frac{\lambda_{B}-\lambda_{A}}{\lambda_{B}}
\end{gathered}
$$

$$
\lambda_{B}-\lambda_{A}=-\lambda_{B} \frac{\theta_{s} \Delta \theta_{A}}{\theta_{s} \theta_{A}-\theta_{A}^{2}-\theta_{A} \Delta \theta_{A}}
$$

Now since $\lambda_{B}-\lambda_{A}$ need never be known to better than about 10 percent, it is evident for the case in question, where $\theta_{s}=2 \theta_{A}=2,600^{\circ} \mathrm{K}$., that $\theta_{s}$ and $\theta_{A}$ need be known only approximately, say to the nearest $100^{\circ}$ or $200^{\circ} \mathrm{K}$., and that the term $\theta_{A} \Delta \theta_{A}$ may be neglected. $\lambda_{B}$ is approximately $0.65 \mu$ and consequently

$$
\frac{\lambda_{B}-\lambda_{A}}{\Delta \theta_{A}}=-0.001 \mu / \text { degree }
$$

\begin{tabular}{|c|c|c|c|}
\hline Observer A & $\lambda_{A}$ & $\lambda_{H . T . W}-\lambda_{A}$ & $\lambda_{H \cdot \text { T.W. }}$ \\
\hline \multirow[t]{2}{*}{$\begin{array}{l}\text { E.C.C } \\
\text { G.E.M } \\
\text { R.F.J } \\
\text { C.F.S } \\
\text { A.Q.T } \\
\text { K.S.G } \\
\text { F.P.P } \\
\text { I.C.G }\end{array}$} & $\begin{array}{c}\mu \\
0.6522 \\
.6519 \\
.6526 \\
.6522 \\
.6516 \\
.6515 \\
.6521 \\
.6521\end{array}$ & $\begin{array}{c}\mu \\
0.0000 \\
+.0001 \\
-.0001 \\
.0000 \\
+.0002 \\
+.0003 \\
+.0003 \\
+.0003\end{array}$ & $\begin{array}{l}\mu \\
0.6522 \\
.6520 \\
.6525 \\
.6522 \\
.6518 \\
.6518 \\
.6518 \\
.6524\end{array}$ \\
\hline & $.6520_{3}$ & & $.6520 \theta$ \\
\hline
\end{tabular}

The minus sign means that the effective wave length is greater for the observer whose setting of the pyrometer is the lower. The result of this determination is shown in the following table for one observer:

TABLE 2.-Effective wave length of observer H.T.W.

This indirectly obtained value, since it is based on the visibility data of eight observers, is unquestionably more accurate than the value 0.6522 previously used for the observer in question, but the difference is small enough to be neglected.

The effective wave lengths for the four observers are given in table 3 . 
TABLE 3.-Effective wave length for the obscrvers used in this investigation

\begin{tabular}{|r|r|}
\hline \multicolumn{1}{|c|}{ Observer } & $\lambda$ \\
\hline F.H & \\
H.T.W. & 0.6530 \\
W.F.R.R. & .6521 \\
F.R.C. & .6522 \\
Mean & .6526 \\
\hline
\end{tabular}

\section{RESULTS}

The method of calculating the temperatures from the obscrved ratio of brightness and the effective wave length is described in previous work on the freezing point of platinum. ${ }^{21}$ When the avernge effective wave length for the four observers is used to calculate the results (based on the gold point) of the individual freezes, the mean values for the individual observers range from $2,451^{\circ}$ to $2,455^{\circ} \mathrm{C}$. When, however, each freeze is calculated on the basis of the eflective wave length for the man who observed that freeze, the values shown in the left half of table 4 are obtained. The values based on platinum are not greatly affected by the value of the effective wave length used. In this latter work, the illumination of the photometric field of the pyrometer was somewhat too high for precise matching and accounts for the larger scatter of the results obtained. These variations, however, are random in nature and the mean value is nearly as good as the one based un gold.

TABLE 4.-Summary of determinations of the freezing point of iridium

\begin{tabular}{|c|c|c|c|c|c|c|c|c|}
\hline \multicolumn{5}{|c|}{ Values based on gold point, $1,063^{\circ} \mathrm{C}$. } & \multicolumn{4}{|c|}{ Values based on platinum point, $1,773.5^{\circ} \mathrm{C}$. } \\
\hline Freeze nos. ${ }^{1}$ & F.H. & H.T.W. & W.F.R. & F.R.C. & Freeze nos. & H.T.W. & W.F.R. & F.R.C. \\
\hline $\begin{array}{l}1,2,3,5 \\
4,6,7,9 \\
8\end{array}$ & $\begin{array}{c}{ }^{\circ} C . \\
2,452.5 \\
2,452.4 \\
2,452.9\end{array}$ & $\begin{array}{c}{ }^{\circ} \mathrm{C} . \\
2,453.2 \\
2,452.9\end{array}$ & $\begin{array}{c}{ }^{\circ} \mathrm{C} . \\
2,453.5 \\
2,452.5\end{array}$ & $\begin{array}{c}{ }^{\circ} \mathrm{C} . \\
2,452.3 \\
2,454.9 .\end{array}$ & \multirow{2}{*}{$\begin{array}{r}1,2,3 \\
4,5,6 \ldots \\
7,8,9 \\
10,11,12 \\
\quad \text { Mean.... }\end{array}$} & $\begin{array}{c}{ }^{\circ} \mathrm{C} . \\
2,458.2 \\
2,455.8 \\
2,455.0 \\
2,454.1\end{array}$ & $\begin{array}{l}{ }^{\circ} \mathrm{C} . \\
2,454.4 \\
2,451.8 \\
2,453.9 \\
2,453.7\end{array}$ & $\begin{array}{l}{ }^{\circ} \mathrm{C} \\
2,456.6 \\
2,45.4 .4 \\
2,455.1 \\
2,455.5\end{array}$ \\
\hline Mean.... & $2,452.6$ & $2,453.0$ & $2,453.0$ & $2,453.6$ & & $2,455.8$ & $2,453.7$ & $2,455.5$ \\
\hline
\end{tabular}

1 The observers of the freezes are listed in the columns of the table in the same order as the frceze num thers are given in this column, thus freeze no. 3 goes with W.F.R.

The difference of $2^{\circ} \mathrm{C}$. between the freezing point value based upon the gold point and that based upon the platinum point is not surprising in view of the fact that each of these separate values is considered to be accurate only to $\pm 3^{\circ} \mathrm{C}$. The consistently higher values obtained in the latter case indicate that the difference is not due solely to accidental errors in making the pyrometric settings.

In column 2 of table 5 are listed three ratios of brightness, all measured with black bodies immersed in freezing metals. In measuring such ratios, the greatest ratio is most sensitive to errors in the effective wave length and in the measured sector disk openings. 'The iridium to platinum ratio should therefore be the most accurately

21 See footnote 18, p. 814. 
known of the three. The value for the iridium point based on this ratio, however, is not necessarily the best one since the uncertainty in the platinum point enters directly into this and moreover the observations are not as precise.

TABLE 5.-Summary of ratios of brightness and corresponding temperatures of fixed points

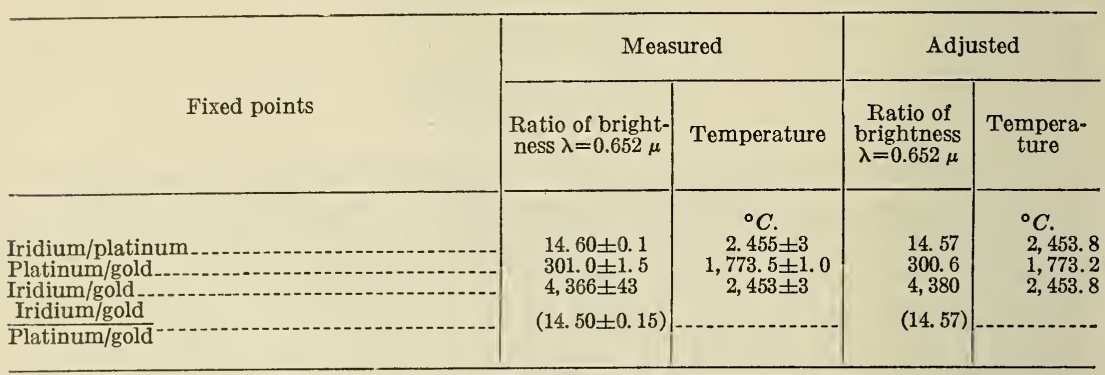

The three ratios in table 5 have been adjusted by the usual method for the adjustment of conditioned observations. These adjusted values, shown in column 4 , indicate that the platinum point is probably lower than $1,773.5^{\circ} \mathrm{C}$. From this it is concluded that:

Freezing point of platinum $=1,773^{\circ} \pm 1^{\circ} \mathrm{C}$. (Int.).

Freezing point of iridium $=2,454^{\circ} \pm 3^{\circ} \mathrm{C}$. (Int.).

The errors entering into the determination are somewhat difficult to evaluate. A summary of the estimated errors is given in table 6 . The probable errors are all very much smaller and it is reasonably certain that the actual errors do not exceed those listed in the table.

\section{TABLE 6.-Summary of estimated errors}

\begin{tabular}{|c|c|c|}
\hline \multirow[b]{2}{*}{ Sources of error } & \multicolumn{2}{|c|}{ Equivalent in ${ }^{\circ} \mathrm{C}$. } \\
\hline & $\begin{array}{c}\text { Work based } \\
\text { on gold } \\
\text { point }\end{array}$ & $\begin{array}{l}\text { Work based } \\
\text { on plati- } \\
\text { num point }\end{array}$ \\
\hline $\begin{array}{l}\text { Transmission of sectors } \\
\text { Effective wave length } \\
\text { Photometric matching } \\
\text { Departure from black body conditions } \\
\text { Impurity of metal } \\
\text { Reference temperature }\end{array}$ & $\begin{array}{r}{ }^{\circ} \mathrm{C} . \\
0.5 \\
1.0 \\
.5 \\
.7 \\
1.0 \\
0\end{array}$ & $\begin{array}{r}{ }^{\circ} C . \\
0.1 \\
.3 \\
1.0 \\
.7 \\
1.0 \\
1.0\end{array}$ \\
\hline Maximum error if all are of same sign & 3.7 & 4.1 \\
\hline
\end{tabular}

The value based on the direct measurement of the iridium to gold ratio is not dependent upon previous work and is the more reliable. In the absence of the other value, it would be considered good to $\pm 3^{\circ} \mathrm{C}$., since it is not likely that the errors listed are all of the maximum size and also all of the same sign. The satisfactory check obtained in the work based on the platinum point makes the estimate of $\pm 3^{\circ} \mathrm{C}$. for the final result a conservative one. 


\section{SUMMARY}

The ratio of brightness of black bodies immersed in freezing iridium and freezing gold has been determined directly and in terms of the previously measured platinum to gold ratio. 'The platinum point is established as $1,773 \pm 1^{\circ} \mathrm{C}$. and the iridium point as $2,454 \pm 3^{\circ} \mathrm{C}$.

\section{ACKNOWLEDGMENTS}

Acknowledgment is made to Wm. F. Roeser and F. R. Caldwell who gave able assistance throughout the work and served as observers.

\section{APPENDIX. PREPARATION AND PURITY OF THE IRIDIUM}

By Edward Wichers

The purification of iridium is attended by unusual difficulties. 'The iterature on iridium does not include methods which can be depended upon for the complete elimination of impurities, even though they may be satisfactory for preparing metal of commercial purity. For this reason, and because the preparation of specimens of demonstrated purity has not been described, it seems rather unlikely that iridium of very high purity has been previously prepared.

All of the base metals ordinarily associated with iridium, as well as silver, gold, and probably palladium, can be removed by precipitating the iridium several times as ammonium chloroiridate, $\left(\mathrm{NH}_{4}\right)_{2} \mathrm{ICCl}_{6}$, provided proper precautions are taken. Platinum and ruthenium, on the other hand, cannot be separated from iridium in this way because they form chloro salts of the same order of solubility as the iridium salt. Even rhodium, which does not form an analogous, slightly soluble chloro salt, will contaminate the iridium compound with the utmost persistence, so that it is wholly impracticable, if not impossible, to get rid of rhodium in this way. No difficulty is experienced with osmium, although it forms a chloro salt sinilar to iridium, because it is volatilized as the tetroxide when the solution is digested with nitric acid or aqua regia, which is done repeatedly in the usual refining process.

When iridium is precipitated as ammonium iridium nitrite, platinum and ruthenium concentrate rapidly in the mother liquors and could probably be completely eliminated by several precipitations of that salt. This procedure can also be adapted to the separation of most of the base metals. However, in this instance it is rhodium which forms an analogous salt, somewhat less soluble than the iridium compound. Hence rhodium could be eliminated only by a long continued process of fractional precipitation, which is not very suitable when only a limited amount of material is available, and which in any case is not favorable to the purification of the more soluble of the two salts. Such a method would be better for freeing rhodium of iridium than vice versa.

Up to the present time no slightly soluble, easily handled, compound of iridium has been thought of which can be repeatedly precipitated and thereby effect the complete removal of rhodium. Small scule experiments, similar to an analytical procedure which has been de- 
veloped in this laboratory ${ }^{22}$ for the separation of rhodium from iridium, have shown that iridium can be freed of rhodium by precipitating the latter with trivalent titantium compounds. However, this reaction is not very practicable for even laboratory-scale refining operations. Earlier work ${ }^{23}$ indicated that ruthenium could be eliminated by fractional precipitation with hydrogen sulphide, but that the yield of iridium was not very favorable. Later work has shown that this treatment also gets rid of rhodium and platinum. The poor yield (sometimes only 50 percent of fairly pure starting material) is offset by the simplicity of the operation and the fact that all three of the most persistent impurities are eliminated together. The procedure consists in saturating the acidified chloride solution (50 g of metal and $50 \mathrm{ml}$ of concentrated hydrochloric acid per liter has been found to give satisfactory conditions of concentration) with hydrogen sulphide at room temperature and keeping it saturated for a week or longer, during which time platinum, rhodium, ruthenium, etc., slowly precipitate, together with a portion of the iridium. The precipitation is stopped when spectrographic examination of the iridium obtained from the filtered solutions shows no trace of other platinum metals. Foreign metals which are not completely precipitated by hydrogen sulphide at the prevailing acidity are then removed by repeated precipitation of ammonium chloroiridate, sometimes combined with one or more precipitations of ammonium iridium nitrite.

The iridium sponge, from which the ingot was prepared which was used in the experimental work described in this paper, was purified in two lots by the foregoing procedure, by H. A. Buchheit and R. K. Bell. The starting material was crude iridium residues from various sources, mostly obtained in the process of platinum refining by the United States Assay Office at New York, a portion of which was lent by the United States Mint and a portion obtained from the War Department. The crude residues contained large amounts of the remaining platinum metals, especially rhodium and platinum, as well as tin, iron, and other base metals. The iridium content of the residues probably averaged less than 25 percent.

After getting the residues into solution, mostly by fusion with alkaline oxidizing reagents, the iridium was concentrated somewhat by various procedures commonly employed to separate the platinum metals from each other and from base metals. The partially concentrated material was then subjected to fractional precipitation with hydrogen sulphide. One of the two lots, comprising about 60 percent of the metal used in the ingot, was finally purified from small amounts of base metals present, by twice converting the chloride solution to a nitrite solution (by heating with sodium nitrite), followed by the addition of ammonium chloride to precipitate ammonium iridium nitrite, and twice precipitating ammonium chloroiridate. The final purification of the other lot consisted in six precipitations as ammonium chloroiridate. Both lots of the ammonium chloroiridate were ignited and reduced under hydrogen to iridium sponge, samples of which were examined spectrographically to make sure that the material was of satisfactory purity.

\footnotetext{
${ }_{22}$ R. Gilchrist, B.S. Jour. Research, vol. 9, p. 547, 1932.

${ }^{23}$ E. Wichers, R. Gilchrist, and W. H. Swanger, Purification of the Six Platinum Metals, Trans. Am.
} 
After the completion of the work with the ingot, the arc spectrum of the metal ${ }^{24}$ was photographed and compared with the arc spectrum of a sample of iridium sponge to which 0.02 percent each of platinum, rhodium, ruthenium, iron, and thorium (the last as oxide) had been added. The spectrum of the ingot showed no traces of any of the other platinum metals nor any other impurities except a faint trace of iron and silicon.

A further comparison of the ingot was then made with standards to which had been added 0.01 and 0.003 percent of iron. The intensity of the iron lines in the spectrum of the ingot was much less than in that of either standard and indicated the amount of iron to be 0.001 percent or less.

No standard containing silicon was prepared, but the ingot showed only a faint trace of the very sensitive line of wave length 2,SS1 $\mathrm{A}$.

Spectrograms of standards which contained smaller admixtures of rhodium, ruthenium, platinum, and thorium than the one with which the ingot was directly compared, indicate that 0.002 percent of ruthenium and 0.005 percent of thorium would have been detected if present in the ingot. The sensitivity of rhodium was less well defined, but is probably of the same order as that of ruthenium. The sensitivity of platinum in these spectra may be limited to about 0.005 percent. However, experience in purifying iridium by fractional precipitation with hydrogen sulphide shows that platinum is eliminated much more rapidly than either rhodium or ruthenium. Hence it is highly probable that the amount of platinum, as well as of rhodium and ruthenium, was below 0.002 percent in each case. Osmium (and palladium) are usually removed in the preliminary purification and have never been detected during the final stages of purification. On the basis of both chemical and spectrographic evidence it seems reasonable to conclude that the iridium ingot, at the completion of the experimental work, contained less than a total of 0.01 percent of metallic impurities.

Washington, March 1, 1933.

24 The spectrographic analyses were made by W. F. Meggers and B. F. Scribner. 